\section{Práticas de atenção ao parto e os desafios para humanização do cuidado em dois hospitais vinculados ao Sistema Único de Saúde em município da Região Sul do Brasil}

\author{
Childbirth practices and challenges for \\ humanization of care in two public \\ hospitals in Southern Brazil
}

\footnotetext{
${ }^{1}$ Hospital Universitário de Maringá, Universidade Estadual de Maringá Maringá, Brasil. 2 Faculdade de Ciências Médicas, Universidade Estadual de Campinas, Campinas, Brasil.

Correspondência E. E. I. Nagahama Hospital Universitário de Maringá, Universidade Estadual de Maringá. Av. Mandacaru 1590 Maringá, $P R$ 87083-240, Brasil. enagahama@pop.com.br
}

\begin{abstract}
The aim of this study was to characterize hospital care for childbirth in two hospitals affiliated with the Unified National Health System in Maringá, Paraná, Brazil, and identify both obstacles and facilitating factors for the implementation of humanized care, based on women's perception of the care received. This was an exploratory and descriptive study with a cross-sectional design, analyzing hospital patient charts and interviews with 569 women who gave birth at the two hospitals from March 2005 to February 2006. Hospital care was characterized on the basis of WHO quality-of-care guidelines for labor and delivery. The data pointed to a healthcare model marked by the hygienist legacy in physician-centered hospital protocols and professional practices. Institutional factors, identified as difficulties in institutional and infrastructure organization, hospital protocols, and health professionals' individual practices and stances, denote barriers that jointly hinder the implementation of a humanized model for childbirth care.
\end{abstract}

Parturition; Maternal-Child Health Services; Humanization of Assistance; Professional Practice
Elizabeth Eriko Ishida Nagahama 1

Silvia Maria Santiago 2

\section{Introdução}

A maternidade constitui uma das mais importantes experiências físicas, psicológicas e intersubjetivas na vida das mulheres. O parto, enquanto episódio fisiológico, representa o ápice dos fenômenos bioquímicos e, enquanto evento emocional, psíquico e existencial, é a própria transcendência 1 .

Com a evolução das ciências médicas e a busca pelo acesso aos bens e serviços e o concomitante desenvolvimento técnico-científico, a assistência ao parto e nascimento passou a ser objeto de estudo, tendo como princípio norteador a busca de mulheres e bebês saudáveis e seguros 2. Na década de 1980, a discussão sobre os modelos de assistência ao parto levou à discussão entre o modelo baseado na parteira, ou holístico, o modelo médico, ou tecnocrático, e o modelo humanista, problematizando-se os conflitos filosóficos, corporativos e financeiros envolvidos 2 .

$\mathrm{O}$ paradigma humanista, centrado na mu lher, fundamentado na medicina baseada em evidências e no respeito aos direitos das usuárias, constitui o modelo de atenção que tem sido preconizado em substituição ao paradigma hegemônico, focalizado nas intervenções médicas e no uso abusivo de tecnologias 3 . A proposição e a concretização de mudanças rumo a esse atendimento humanizado também podem ser vistas em experiências institucionais, nas quais 
se encontram as ações decisivas de profissionais identificados com o ideário do movimento. Esse modelo de atenção tem se multiplicado e vem avançando continuamente no país 4 .

Considerando que a qualificação e a humanização são características essenciais da atenção obstétrica e neonatal a ser prestada pelos serviços de saúde 5 , e a necessidade de conhecer a assistência prestada às parturientes atendidas em dois hospitais vinculados ao Sistema Único de Saúde (SUS) no Município de Maringá, Estado do Paraná, este estudo objetivou caracterizar a assistência hospitalar ao parto e identificar obstáculos e aspectos facilitadores para implantação do cuidado humanizado, pautando-se na percepção das mulheres sobre a atenção recebida.

\section{Material e método}

Trata-se de estudo exploratório-descritivo, com desenho transversal, conduzido mediante pesquisa em prontuário hospitalar e entrevistas realizadas com puérperas que tiveram o parto vaginal ou cesáreo nos dois hospitais de referência para parto SUS no Município de Maringá, no período de $1^{\circ}$ de março de 2005 a 28 de fevereiro de 2006.

Para a obtenção da amostragem, realizou-se o levantamento do número de partos SUS ocorridos no período de março de 2004 a fevereiro de 2005, por meio dos dados contidos no livro de registro de nascidos vivos dos dois hospitais. Esse procedimento permitiu projetar o tamanho da amostra para o período de março de 2005 a fevereiro de 2006, calculado com $95 \%$ de confiança e erro máximo de $5 \%$. Estimou-se uma amostra para cada hospital, estratificada por tipo de parto e mês, que totalizou 569 mulheres, sendo 259 no hospital 1 (136 partos cesáreos e 123 vaginais) e 310 no hospital 2 (160 partos cesáreos e 150 vaginais).

Cinco entrevistadoras aplicaram questionário, contendo questões abertas e fechadas, no alojamento conjunto de cada hospital, entre o primeiro e terceiro dias de puerpério, após leitura e assinatura do termo de consentimento. O questionário constituiu-se de duas partes: a primeira objetivou a transcrição de informações demográficas, sociais e história reprodutiva constantes no prontuário hospitalar. A segunda englobou questões que apontaram a existência de práticas humanizadas na assistência no trabalho de parto e durante o parto, cujas respostas foram obtidas pela técnica da entrevista estruturada. A autora realizou a supervisão do trabalho de campo e, mensalmente, avaliou-se o alcance do tamanho da amostra estimada para o período.
No transcorrer do trabalho de campo, $37 \mathrm{mu}$ lheres sorteadas como sujeitos de pesquisa não foram entrevistadas pelos seguintes motivos: ocorrência do parto fora do ambiente hospitalar (2), ocorrência de óbito fetal (3), recusa em participar da pesquisa (9) e puérpera menor de 18 anos sem acompanhante que autorizasse a realização da entrevista (23). Não houve recusa em participar da pesquisa.

A caracterização da assistência hospitalar foi realizada com base em quatro indicadores de qualidade na assistência no trabalho de parto e no parto recomendados pela Organização Mundial da Saúde (OMS): (1) receber informações que desejasse no trabalho de parto e no parto; (2) uso de métodos não-invasivos e não-farmacológicos de alívio da dor no trabalho de parto; (3) presença do acompanhante de escolha da parturiente no trabalho de parto e no parto; (4) contato precoce pele a pele entre mãe e filho em sala de parto. A escolha desses indicadores fundamentou-se em sua representatividade, pois caracterizam a mudança do paradigma tecnocrático da assistência para o modelo humanista 3 .

Para identificar os obstáculos e aspectos facilitadores à implantação do modelo humanizado na assistência ao parto e nascimento, as respostas das entrevistas com as puérperas foram digitadas em banco de dados do Access (Microsoft Corp., Estados Unidos) e transportadas para os programas Excel (Microsoft Corp., Estados Unidos) e Statistica 6.0 (Statsoft Inc.; http://www.statsoft. com), nos quais realizou-se a análise exploratória dos dados. Por meio da leitura e análise desse material criaram-se categorias para agrupar as variáveis qualitativas, que foram classificadas com a ajuda do programa Sphinx Léxica 4.5 (Sphynx Software Solutions Incorp., Washington DC, Estados Unidos). Para qualificar os resultados apresentados, as falas consideradas ilustrativas da categoria em análise foram transcritas.

A pesquisa foi aprovada pelo Comitê de Ética em Pesquisa da Universidade Estadual de Maringá e da Universidade Estadual de Campinas, sendo a coleta de dados autorizada nas duas instituições.

\section{Resultados e discussão}

\section{Características da atenção hospitalar ao parto SUS}

O Município de Maringá aderiu em 2002 às diretrizes propostas no Programa de Humanização no Pré-natal e Nascimento (PHPN) do Ministério da Saúde ${ }^{6}$. Dentre os dez hospitais do município, dois constituíram referência para atendimento a partos SUS. O hospital 1 caracteriza-se como 
sendo de caráter público, hospital ensino; conquistou o título de Hospital Amigo da Criança em 2003 e constitui referência no atendimento a gestantes de alto risco da macrorregião noroeste do Paraná e para gestantes de baixo e alto riscos atendidas em quatro unidades básicas de saúde do município. O hospital 2, credenciado pelo SUS, constitui hospital geral, beneficente, sem fins lucrativos e é referência para atendimento hospitalar ao parto para gestantes de baixo e alto riscos atendidas em 19 unidades básicas de saúde do município.

\section{Características sócio-demográficas} e obstétricas

As mulheres entrevistadas tinham a média de 25 anos (desvio-padrão de 6,4), variando de 12 a 46 anos. Nas faixas etárias extremas do período reprodutivo, encontravam-se $24,3 \%$ com menos de 19 anos e $6,7 \%$ com idade superior a 35 anos. Grande parte das mulheres convivia com parceiro $(74,8 \%)$ e residia no Município de Maringá (76,4\%). Quanto à escolaridade, 28,8\% freqüentaram o primeiro grau, $65,9 \%$ o segundo grau completo, 4,4\% estudaram até o nível superior e $0,9 \%$ foi classificada como analfabeta.

No que se refere à inserção no mercado de trabalho, 62,9\% das mulheres não exerciam atividade econômica. Em relação à história reprodutiva, 39,9\% eram primigestas e, como resultado da gestação, encontrou-se 16,3\% de abortamentos.

Quanto à taxa de cesarianas, obteve-se uma amostra de $52,5 \%$ no hospital 1 e $51,6 \%$ no hospital 2.

A época da ocorrência do parto variou de 25 a 42 semanas, com a média de 39,1 semanas de gestação (desvio-padrão de 1,08). A maioria das mulheres $(81,5 \%)$ teve o parto a termo (37-42 semanas incompletas de gestação), 16,7\% corresponderam à condição de pré-termo (menos de 37 semanas de gestação) e 1,8\% foi classificada como pós-termo (42 semanas e mais de gestação). A grande maioria dos recém-nascidos (99,5\%) obteve escore de Apgar entre 7 a 10 no quinto minuto de vida, ou seja, nasceram em boas condições de vitalidade.

Características da assistência hospitalar ao parto segundo indicadores de qualidade, obstáculos e aspectos facilitadores

- Indicador 1: receber informações que desejasse no trabalho de parto e no parto

O grau de informação na assistência no trabalho de parto e no parto tem sido mostrado como fa- tor de grande relevância para as mulheres, por aumentar a percepção de estar no controle interno (relacionado ao próprio comportamento) e externo (referente ao ambiente, incluindo a equipe de saúde), facilitar a compreensão sobre o cuidado realizado 7 e possibilitar maior participação nos processos decisórios 8,9. Para as mulheres, receber informação suficiente e adequada é sinônimo de humanização 10 , representa o cuidado na atenção 11 e constitui característica desejável de um profissional competente 12.

As informações mais freqüentes recebidas pelas mulheres no trabalho de parto foram as relativas à progressão do trabalho de parto $(30,1 \%)$, indicação do parto cesáreo $(17,9 \%)$ e procedimentos de rotina $(13,2 \%)$.

Outras informações consideradas desejáveis, relatadas com pouca freqüência pelas mulheres, foram sobre o uso de métodos não-farmacológicos para alívio da dor $(2,4 \%)$, aleitamento materno $(1,2 \%)$, liberdade de posição e de movimentação $(0,5 \%)$, estímulo ao parto vaginal $(0,4 \%)$, participação do acompanhante no trabalho de parto $(0,2 \%)$, líquidos via oral $(0,1 \%)$ e se desejavam parto vaginal ou cesáreo $(0,1 \%)$. Por outro lado, orientar os familiares sobre a evolução do trabalho de parto e a possibilidade de receber analgesia no parto não foram citados pelas entrevistadas. Esses são achados semelhantes aos registrados em outros estudos brasileiros, os quais confirmam que as informações recebidas no trabalho de parto são variáveis e, de modo geral, insuficientes. Autores descrevem um atendimento marcado pela repetição automática de procedimentos técnicos e, somente quando indicado o parto cesáreo, o nível de informação torna-se mais completo. Essa característica no atendimento foi observada tanto para mulheres atendidas em maternidades públicas quanto nas conveniadas ao SUS 13,14,15,16.

O relato de algumas mulheres revela atitude autoritária e relação assimétrica entre profissional de saúde e parturientes. Ante elas, as mulheres perdem autonomia e têm dificuldades em fazer valer seus direitos à informação.

"Ele disse que doía mesmo, que todo mundo sentia a mesma coisa" (26 anos, multípara).

"As enfermeiras nem conversaram comigo, só mostraram onde era minha cama e só, não explicaram nada, não falaram se eu podia tomar banho, nada, não falaram nada" (21 anos, primípara).

Quanto às informações recebidas no parto, chama atenção o percentual de mulheres que destacou o apoio verbal e não-verbal manifestado pelos profissionais de saúde $(24,3 \%)$, seguido dos procedimentos de rotina $(16,6 \%)$, da anestesia para a cesárea e coordenação dos esforços 
expulsivos (13,5\%). Isso pode ser referido ao fato de que, no relacionamento da mulher com a equipe de saúde, o fator emocional é tido como um dos que mais afetam a memória das mulheres em relação à experiência do parto e do nascimento ${ }^{8,17}$. Por outro lado, informações desejáveis foram pouco manifestadas na assistência, como ser questionada sobre a posição desejada no parto $(2,6 \%)$, condições de nascimento $(2,6 \%)$, episiotomia e episiorrafia $(2,1 \%)$, dequitação da placenta $(0,5 \%)$ e ser informada do nome e categoria profissional de quem a atendeu $(0,2 \%)$. Outras informações relevantes não foram mencionadas pelas mulheres, tais como o estímulo ao aleitamento materno, informar o sexo do bebê, clampeamento do cordão, participação do acompanhante, contato precoce com o recém-nascido e congratulações com o nascimento.

Portanto, os dados apontam para o atendimento no qual as informações prestadas pelos profissionais constituíram reflexo de suas atitudes no cotidiano. Só se explica ou se orienta o que é praxe na assistência e pouco se oportuniza à mulher escolhas, seja em relação aos aspectos técnicos ou que envolvam apoio no parto.

Observou-se, em alguns casos, a negação da informação, relatada por algumas mulheres:

“Ninguém entrou lá, como poderia explicar algo?” (37 anos, multípara).

"Eu fiquei agoniada, eu queria saber como eu tava, como tava o bebê, eles não falaram nada para mim, é muito ruim não saber a vida do meu filho" (18 anos, multípara).

Segundo Alves \& Silva 13, negar informações constitui uma das expressões da violência institucional à parturiente, ou seja, agressão pela negação. Para os autores, as relações de poder desiguais também explicam esses fatos, visto que os médicos consideram as mulheres com menor escolaridade incapazes de entender informações e, portanto, a tentativa de explicação seria infrutífera, representando perda de tempo.

As atitudes repreensivas dos profissionais de saúde, quando as parturientes perdem o controle interno na presença da dor, foram relatadas por algumas mulheres, evidenciadas nas ordens impostas pelo profissional de saúde:

"Eles só mandavam não gritar. Eu queria saber o porquê saía aquilo de mim, mas ninguém falava nada" (30 anos, multípara).

"Só falaram: não faz isso, não faz isso" (29 anos, multípara).

Segundo Tornquist 18, as situações de descompensação da parturiente são justamente aquelas nas quais o respeito ao processo fisiológico da mulher e às suas decisões é substituído pela decisão médica convencional, com desqualificações e infantilização das parturientes. Essas atitudes revelam as dificuldades para enfrentar as situações de descompensação ou de expressões inusitadas de dor e sofrimento das mulheres. Esse dado é significante, à medida em que a escuta da dor e o respeito às suas variadas expressões constituem pontos importantes na avaliação qualitativa da humanização da assistência, porque implica o respeito aos direitos sexuais e reprodutivos das mulheres.

Sobre esse tema, McCallum \& Reis 19 descrevem a atitude de resignação de parturientes adolescentes quanto à situação de subordinação aos profissionais de saúde, na qual disseram saber que era obrigatório, para a realização do parto, obedecer a instruções como o "deitar e ficar quieta", na sala de pré-parto, ou "fechar a boca, abrir as pernas e fazer força”, na sala de parto.

Sobre a atitude dos profissionais em sala de parto, Moraes 20 chama atenção para o fato de os profissionais considerarem a esta sala como qualquer ambiente comum de trabalho, em harmonia com a ética da produção industrial. Essa postura contraria, de forma determinante, os princípios da autonomia e de direitos da mulher no trabalho de parto e durante o parto.

Outro dado que chama atenção refere-se ao fato de que, ser informada sobre a categoria e nome do profissional que assistiu a parturiente, fez parte do relato da minoria das mulheres atendidas no trabalho de parto $(4,2 \%)$ e no parto $(9 \%)$. Isso sugere a despersonalização, impessoalidade e ausência de formação de vínculo, enquanto encontro de subjetividades na assistência ${ }^{21}$. Situação semelhante foi descrita em outros estudos, nos quais as mulheres, além de desconhecerem o nome do profissional que as atendeu, sequer distinguiam a que categoria profissional pertencia $13,14,22$

A Tabela 1 relaciona os profissionais de saúde identificados pelas parturientes como os responsáveis pelas informações realizadas no trabalho de parto e no parto. Pelos motivos descritos acima, a tabela foi construída por categorias profissionais, de forma que o enfermeiro, o técnico de enfermagem e o auxiliar de enfermagem constituíram a categoria equipe de enfermagem, assim como o profissional médico gineco-obstetra e residente de Medicina, a categoria equipe médica. Na sala de parto, a categoria anestesista compreendeu o medico anestesista e o residente de anestesiologia.

No trabalho de parto, chama atenção o fato de que a equipe médica foi a categoria mais citada pelas parturientes como responsável pelas informações recebidas no trabalho de parto nos dois hospitais $(66,8 \%)$, em contraste com a equipe de enfermagem $(10,1 \%)$, composta por 
Profissionais de saúde que realizaram orientações no trabalho de parto e parto a parturientes atendidas em dois hospitais vinculados ao SUS. Maringá, Paraná, Brasil, março de 2005 a fevereiro de 2006.

\begin{tabular}{|c|c|c|c|c|c|c|}
\hline \multirow[t]{2}{*}{ Variáveis } & \multicolumn{2}{|c|}{ Hospital 1} & \multicolumn{2}{|c|}{ Hospital 2} & \multicolumn{2}{|c|}{ Total } \\
\hline & n & $\%$ & n & $\%$ & n & $\%$ \\
\hline \multicolumn{7}{|l|}{ Trabalho de parto } \\
\hline Equipe médica & 93 & 55,7 & 179 & 74,6 & 272 & 66,8 \\
\hline Equipe médica/Equipe de enfermagem & 29 & 17,3 & 39 & 16,3 & 68 & 16,7 \\
\hline Equipe de enfermagem & 21 & 12,6 & 20 & 8,3 & 41 & 10,1 \\
\hline Aluno de Medicina/Aluno de Enfermagem & 15 & 9,0 & - & - & 15 & 3,7 \\
\hline Não identificou & 7 & 4,2 & - & - & 7 & 1,7 \\
\hline Fisioterapeuta/Assistente social & 2 & 1,2 & 2 & 0,8 & 4 & 1,0 \\
\hline \multicolumn{7}{|l|}{ Parto } \\
\hline Anestesista & 17 & 10,2 & 167 & 65,7 & 184 & 43,8 \\
\hline Equipe médica & 75 & 45,2 & 33 & 13,0 & 108 & 25,7 \\
\hline Equipe médica/Equipe de enfermagem & 48 & 29,0 & 38 & 15,0 & 86 & 20,5 \\
\hline Não identificou & 16 & 9,6 & 6 & 2,4 & 22 & 5,2 \\
\hline Equipe de enfermagem & 9 & 5,4 & 9 & 3,5 & 18 & 4,3 \\
\hline Pediatra & 1 & 0,6 & 1 & 0,4 & 2 & 0,5 \\
\hline
\end{tabular}

profissionais que permanecem 24 horas, ininterruptamente, no ambiente hospitalar.

Em relação ao profissional responsável pelas orientações no parto, foi relevante a identificação do profissional anestesista no hospital 2 (65,7\%). Por outro lado, essa condição inverteuse no hospital 1, já que o profissional mais citado pelas mulheres foi o médico que realizou o parto $(45,2 \%)$. Apesar de os hospitais disporem, rotineiramente, da presença do pediatra para recepcionar o recém-nascido na sala de parto, a participação deste foi pequena $(0,5 \%)$, assim como da equipe de enfermagem $(4,3 \%)$.

Alguns trabalhos descrevem que a orientação e informação constituem categorias reveladas como sinônimos de humanização do cuidado na assistência obstétrica para enfermeiros atuantes em maternidades e centros obstétricos. Contudo, essas mesmas pesquisas apontam que, na prática, a participação desses profissionais parece inexpressiva ${ }^{11}$. Esse fato pode ser explicado, dentre outros, à incorporação recente de outros profissionais no cenário do parto, como a doula e as enfermeiras, cuja atuação representa, por vezes, fonte de conflito e de disputa no estabelecimento de condutas de atenção à parturiente ${ }^{4,23}$.
- Indicador 2: uso de métodos nãoinvasivos e não-farmacológicos de alívio da dor no trabalho de parto

A OMS recomenda amplamente o uso dos métodos não-farmacológicos de alívio da dor pela possibilidade de produzir muitos benefícios para a maior parte das mulheres, que não são obtidos com o uso de qualquer outro método farmacológico de alívio da dor 24 . Além disso, a não utilização da analgesia farmacológica permite à mulher mais controle sobre o processo parturitivo 25 .

Boaretto 14 e Lima \& Leão 25 explicam que, apesar da satisfação da mulher com o seu parto não estar relacionada à ausência da dor, deve-se lembrar que o enfrentamento da dor é condicionado pelo ambiente e pelo suporte que ela recebe dos profissionais e acompanhantes.

Registrou-se que 383 (67,3\%) mulheres receberam pelo menos um dos métodos não-farmacológicos para alívio da dor no trabalho de parto. Os mais utilizados, nos dois hospitais, foram o banho de chuveiro e os exercícios respiratórios $(48,2 \%)$. A massagem foi pouco utilizada $(20,9 \%)$, bem como a musicoterapia (1,6\%). A equipe de enfermagem foi a categoria que utilizou, com maior freqüência, os métodos não-farmacológicos de alívio da dor, em contraste com a equipe médica (Tabela 2).

Essa informação remete ao estudo etnográfico de Hotimsky \& Schraiber 26 sobre a formação médica em obstetrícia. A utilização dos métodos 
Utilização de métodos não-farmacológicos para alívio da dor no trabalho de parto em dois hospitais vinculados ao SUS. Maringá, Paraná, Brasil, março de 2005 a fevereiro de 2006.

\begin{tabular}{|c|c|c|c|c|c|c|}
\hline \multirow[t]{2}{*}{ Métodos não-farmacológicos } & \multicolumn{2}{|c|}{ Hospital 1} & \multicolumn{2}{|c|}{ Hospital 2} & \multicolumn{2}{|c|}{ Total } \\
\hline & $\mathbf{n}$ & $\%$ & $\mathbf{n}$ & $\%$ & n & $\%$ \\
\hline Massagem & 73 & 28,2 & 46 & 14,8 & 119 & 20,9 \\
\hline Banho & 126 & 48,6 & 148 & 47,7 & 274 & 48,2 \\
\hline Música & 2 & 0,8 & 7 & 2,3 & 9 & 1,6 \\
\hline Respiração & 136 & 52,5 & 138 & 44,5 & 274 & 48,2 \\
\hline
\end{tabular}

não-invasivos para alívio da dor no trabalho de parto foi comparada, pelos alunos de Medicina, a um ato de proselitismo e de sarcasmo, de negação ao acesso a uma tecnologia moderna de alívio da dor, ou seja, ligada à idéia de precariedade do modelo de atenção e de retrocesso, que se contrapõe à noção de uma assistência moderna, na qual os avanços tecnológicos da cultura ocidental são incorporados.

Nessa perspectiva, Dias \& Domingues 23 diferenciam a formação profissional do modelo médico com o do enfermeiro obstetra, que é mais voltada para o cuidar e nos aspectos fisiológicos, emocionais e sócio-culturais do processo reprodutivo. Sendo assim, Dias 27 afirma que os médicos, de uma forma geral, não se preocupam em incorporar os elementos da proposta de humanização à sua rotina, sendo o uso de métodos alternativos desvalorizados.

Uma pequena parcela dos acompanhantes das parturientes $(14,7 \%)$ aplicou os métodos não-farmacológicos de alívio da dor, o que indica a necessidade da equipe de saúde orientar e ajudar o acompanhante em seu papel de apoio no trabalho de parto. No hospital 2 registrou-se a presença da doula - mulher treinada que dá suporte físico e apoio emocional à gestante -, que atua em conjunto com um dos médicos plantonistas, uma vez por semana.

\section{- Indicador 3: presença do acompanhante de escolha da parturiente no trabalho de parto e parto}

O acompanhante no trabalho de parto foi mais freqüente no hospital 1 (78\%) do que no $2(41,6 \%)$ e, nos dois hospitais, o pai da criança $(23,4 \%)$, mãe $(18,5 \%)$, irmã, sogra e cunhada $(8,4 \%)$, foram os acompanhantes escolhidos com maior freqüência pela parturiente.

Foi relatado pelas mulheres a resistência inicial da equipe de saúde para aceitar a presença da figura masculina como acompanhante da parturiente, sendo um fenômeno também verificado por outros autores 14,28 .

Vários motivos foram alegados pelos profissionais de saúde para impedir a presença do acompanhante: "são regras do hospital; a lei do acompanhante não vigora; o acompanhante é desnecessário; a internação é pelo SUS; as mulheres da enfermaria ficam sem roupa; não é permitido acompanhante do sexo masculino; muita gente atrapalha; é maior de idade, não precisa; acompanhante só pode ficar se for cesárea".

Apresentaram-se, freqüentemente, os aspectos emocionais/sociais ligados ao acompanhante e/ou às condições da parturiente e, raramente, à instituição e seus limites estruturais ou funcionais. Provavelmente, por isso, cada profissional incumbiu-se em fornecer as mais diferentes versões para impedir a presença do acompanhante.

Outro motivo para a ausência do acompanhamento foi a falta de pessoa disponível que pudesse permanecer na instituição, fato ocorrido no hospital 1. Isso pode ser atribuído às características das mulheres atendidas no hospital 1, semelhantes aos achados por Domingues 29: mulheres com baixa escolaridade, maior número de gestações e partos e, portanto, com menor suporte social.

Outro dado que chama a atenção é o fato de que $26,3 \%$ das entrevistadas não souberam responder os motivos pelos quais não puderam ficar com acompanhante e que desconheciam este direito. Isso aponta não somente para a atitude de resignação e subordinação das mulheres, mas a falha dos serviços de saúde em serem os disseminadores dos direitos reprodutivos das parturientes. Esses são achados semelhantes aos encontrados por Carvalho 28 e McCallum \& Reis 19, que ressaltam a posição de grande passividade que os familiares das parturientes assumem em relação à autoridade hospitalar, mediante o exercício de uma prática institucional que traz a clara mensagem de que o parto não é um assunto de família. 
No parto, apenas sete $(2,7 \%)$ parturientes tiveram acompanhante no hospital 1 e uma $(0,3 \%)$ no hospital 2. A ausência do acompanhante na sala de parto foi, de certa forma, esperada, já que esta ausência foi demarcada desde a admissão da parturiente na maternidade.

Quanto aos motivos impeditivos da presença do acompanhante no parto, as barreiras institucionais foram as que apresentaram maior valor $(81,4 \%)$ e o despreparo do acompanhante para entrar na sala de parto também foi relatado. É importante ressaltar que a preparação do acompanhante não deve ser condição para a participação no parto, já que a literatura descreve que, mesmo os pais que não passaram por nenhum treinamento prévio, atenderam à demanda de apoio às mulheres 28.

Esses achados são semelhantes aos encontrados em outros estudos brasileiros, nos quais as barreiras institucionais, as questões sociais e emocionais do acompanhante constituíram motivos impeditivos para a ausência do acompanhamento no trabalho de parto e no parto 19,28,29,30.

Embora minoritária, é necessário considerar a parcela de mulheres que vieram desacompanhadas para o parto pelo desejo de privacidade, visto que o pleno exercício da diversidade de escolhas com relação ao acompanhamento inclui a opção por estar desacompanhada. No trabalho de parto, 5,8\% das mulheres desejaram permanecer sozinhas e, no parto, encontrou-se o percentual de $1,6 \%$.

Alguns autores 20,30 citam que, de maneira geral, os profissionais de saúde possuem receios e idéias pré-concebidas negativas sobre a presença do acompanhante no contexto do nascimento, indicando que, para implantar um projeto de inserção do acompanhante é necessário preparar previamente a equipe de saúde, o que pode se transformar numa oportunidade para que o serviço também se beneficie desta presença. Em estudo recente, Brüggemann et al. 31 apontaram perspectivas positivas sobre a presença do acompanhante no parto, expressas na boa aceitação da presença do acompanhante, bem como a experiência positiva pela pessoa que desempenhou o papel de provedor de apoio.

Embora os profissionais de saúde tenham papel determinante para implantação da assistência humanizada, autores destacam a influência dos gestores na efetivação da prática nos serviços de saúde.

Boaretto 14, ao investigar o grau de apoio ao PHPN por 20 dirigentes de maternidades da rede SUS, no Rio de Janeiro, observou uma tendência à maior penetração do conjunto de protocolos associados à humanização do parto segundo o tipo de gestor. O acompanhante no trabalho de parto e a política do controle de partos cesáreos foram implantados em 88,9\% dos hospitais municipais, em contraste com outras maternidades vinculadas ao SUS $(27,3 \%)$.

\section{- Indicador 4: contato precoce pele a pele entre mãe e filho em sala de parto}

As práticas relativas ao contato da mãe com seu bebê e ao aleitamento materno na sala de parto são indicadores reveladores da qualidade da atenção no parto humanizado 24 . O passo quatro da Iniciativa Hospital Amigo da Criança (IHAC) preconiza que o início do aleitamento materno deve ocorrer na primeira meia hora após o nascimento, e que os bebês devem permanecer por pelo menos trinta minutos junto à sua pele 32 .

Registrou-se que a maioria $(80,8 \%)$ dos recém-nascidos teve contato pele a pele com sua mãe, mas com tempo inferior a 30 minutos. Somente 40 crianças (7\%) permaneceram por trinta minutos ou mais em contato com sua mãe e 69 $(12,2 \%)$ não tiveram contato em sala de parto. A modalidade mais freqüente de contato foi o rosto $(78,6 \%)$, seio $(38 \%)$, sucção $(6,9 \%)$ e abdômen materno $(6,7 \%)$, todos com tempo de contato inferior a 30 minutos (Tabela 3).

Quando analisado o tempo de contato pele a pele (30 minutos ou mais) com o tipo de parto, registrou-se que apenas 5,3\% dos bebês nascidos de parto vaginal e 1,8\% dos nascidos de parto cesáreo permaneceram por pelo menos trinta minutos com suas mães. Esses dados são preocupantes, visto que o passo quatro da IHAC recomenda que, em $80 \%$ dos partos vaginais e $50 \%$ dos partos cesáreos, o bebê seja colocado em contato pele a pele com a mãe por 30 minutos ou mais. Além disso, ao se considerar que a quase totalidade $(99,5 \%)$ das crianças teve boa vitalidade ao nascimento, os resultados apresentados são injustificáveis.

Apesar de o hospital 1 ter o título de Hospital Amigo da Criança, os dados apresentados ressaltam a necessidade de rever as estratégias para promover efetivamente as ações de promoção do aleitamento materno.

Corrêa 33 , ao analisar como mães e bebês vivenciaram os procedimentos que são realizados referentes ao passo quatro da IHAC em dois hospitais com o título de Hospital Amigo da Criança, na cidade de Santos, também não encontrou resultados satisfatórios. A autora concluiu que $58 \%$ dos bebês foram colocados pele a pele em suas mães, $43 \%$ foram colocados entre os seios, $22 \%$ mamaram na sala de parto e apenas $17 \%$ permaneceram vinte minutos ou mais com suas mães. 
Contato pele a pele entre mãe e filho em sala de parto em dois hospitais vinculados ao SUS. Maringá, Paraná, Brasil, março de 2005 a fevereiro de 2006.

\begin{tabular}{|c|c|c|c|c|c|c|}
\hline \multirow[t]{2}{*}{ Contato em sala de parto } & \multicolumn{2}{|c|}{ Hospital 1} & \multicolumn{2}{|c|}{ Hospital 2} & \multicolumn{2}{|c|}{ Total } \\
\hline & n & $\%$ & n & $\%$ & n & $\%$ \\
\hline Sim & 216 & 83,4 & 284 & 91,6 & 500 & 87,8 \\
\hline 30 minutos ou mais & 39 & 15,1 & 1 & 0,3 & 40 & 7,0 \\
\hline$<30$ minutos & 177 & 68,3 & 283 & 91,3 & 460 & 80,8 \\
\hline Não & 43 & 16,6 & 26 & 8,4 & 69 & 12,2 \\
\hline
\end{tabular}

A revisão da literatura mostrou que o contato visual rápido, precedido por procedimentos de higienização, constitui a forma de contato mais comum 13,14 . Interessante ressaltar os achados de Alves \& Silva 13, que são concordantes com os encontrados neste estudo, nos quais o contato pele a pele foi mais incentivado na maternidade pública que na conveniada, e foi mais freqüente nos partos vaginais do que nos cesáreos.

As práticas relativas ao contato da mãe com seu bebê ao nascer e do aleitamento materno na sala de parto, aliadas à ausência do acompanhante da parturiente, traduzem a idéia de que a sala de parto constitui locus onde o modelo tecnocrático se impõe com maior força.

\section{Considerações finais}

Os dados apontaram para um modelo assistencial marcado pelo peso da herança higienista nas rotinas hospitalares e nas práticas profissionais, centrado no profissional médico como condutor do processo.

Identificaram-se como obstáculos para implantação do cuidado humanizado: o desconhecimento das mulheres e de seus acompanhantes sobre os direitos reprodutivos na atenção ao parto e nascimento; a atitude de resignação das mulheres e de seus familiares; a falta de orientação e preparo do acompanhante; a relação assimétrica entre profissional de saúde e parturiente; a insuficiência e negação da informação; as más condições estruturais; o despreparo da equipe para acolher o acompanhante; a participação incipiente da equipe multiprofissional na assistência; a prática institucional e profissional, que não incorporou integralmente ao cuidado obstétrico a idéia do parto como evento familiar e direito reprodutivo.

Por outro lado, a adesão da equipe de enfermagem aos métodos não-farmacológicos de alívio da dor, a presença da doula no hospital 2 , a permissão do acompanhante no trabalho de parto para a maioria das mulheres no hospital 1, a inserção do acompanhante masculino, o apoio verbal e não-verbal dos profissionais de saúde, o acolhimento da parturiente e a atuação do profissional anestesista constituem aspectos positivos que contribuíram para a humanização do cuidado.

$\mathrm{O}$ estudo indicou que os fatores institucionais, identificados nas dificuldades de organização institucional e na estrutura física, as rotinas hospitalares e, sobretudo, a prática e postura individual dos profissionais de saúde reveladas na fala das mulheres, denotaram barreiras que, em seu conjunto, dificultaram a implantação do modelo humanizado na assistência ao parto e nascimento.

Considerando a existência de evidências científicas que comprovam a efetividade da prática humanizada, é essencial que a formação acadêmica incorpore as mudanças no paradigma de atenção à saúde da mulher, para o enfoque da atenção integral e dos direitos sexuais e reprodutivos; o entrosamento das diversas disciplinas profissionais, com vistas ao trabalho em equipe que garanta a saúde e os direitos das mulheres e de seus recém-nascidos; o preparo da gestante para o parto e nascimento desde o pré-natal; a ampla divulgação dos direitos sexuais e reprodutivos das mulheres na mídia e nos serviços de saúde; a efetiva incorporação do modelo humanizado da atenção como diretriz e filosofia institucional; e, sobretudo, a incorporação de novas atitudes por parte dos profissionais.

Finalmente, concorda-se com Tanaka 34 (p. 47), que afirma: "para uma assistência adequada à gestante, o mais importante é seguir o princípio básico da obstetrícia: obstare, que significa estar ao lado". Ao lado, mas junto, ou, simplesmente, individualizar e qualificar o atendimento - logo, humanizá-lo. 


\section{Resumo}

O objetivo do estudo foi caracterizar a assistência hospitalar ao parto em dois hospitais vinculados ao Sistema Único de Saúde no Município de Maringá, Paraná, Brasil, e identificar obstáculos e aspectos facilitadores para implantação do cuidado humanizado, pautando-se na percepção das mulheres sobre a atenção recebida. Tratou-se de estudo exploratório-descritivo, com desenho transversal, conduzido mediante pesquisa em prontuário hospitalar e entrevistas realizadas com 569 mulheres atendidas nos dois hospitais, no período de março de 2005 a fevereiro de 2006. A caracterização da assistência hospitalar foi realizada tomando-se por base quatro indicadores de qualidade na assistência no trabalho de parto e parto recomendados pela Organização Mundial da Saúde. Os dados apontaram para um modelo assistencial marcado pelo peso da herança higienista nas rotinas hospitalares e nas práticas profissionais, centrado no profissional médico como condutor do processo. Os fatores institucionais, identificados nas dificuldades de organização institucional e na estrutura física, as rotinas hospitalares e, sobretudo, a prática e postura individuais dos profissionais de saúde denotaram barreiras que, em seu conjunto, dificultam a implantação do modelo humanizado na assistência ao parto e nascimento.

Parto; Serviços de Saúde Materno-Infantil; Humanização da Assistência; Prática Profissional

\section{Referências}

1. Stevens CMT. Maternidade e literatura: desconstruindo mitos. In: Swain TN, Muniz DCG, organizadores. Mulheres em ação: práticas discursivas, práticas políticas. Florianópolis: Editora Mulheres/Belo Horizonte: PUC-Minas; 2005. p. 35-72.

2. Diniz CSG. Humanização da assistência ao parto: um diálogo entre a técnica e os direitos humanos [Tese de Doutorado]. São Paulo: Universidade de São Paulo; 2002.

3. Davis-Floyd R. The technocratic, humanistic, and holistic paradigms of childbirth. Int J Gynaecol Obstet 2001; 75:5-23.

4. Dias MAB, Deslandes SF. Humanização da assistência ao parto no serviço público: reflexão sobre desafios profissionais no caminho de sua implementação. In: Deslandes SF, organizadora. Humanização dos cuidados em saúde: conceitos, dilemas e práticas. Rio de Janeiro: Editora Fiocruz: 2006. p. 351-69.

5. Departamento de Ações Programáticas Estratégicas, Secretaria de Atenção à Saúde, Ministério da Saúde. Pré-natal e puerpério: atenção qualificada e humanizada. Manual técnico. Brasília: Ministério da Saúde; 2005. (Serie A. Normas e Manuais Técnicos. Série Direitos Sexuais e Direitos Reprodutivos - Caderno $n^{\circ}$. 5).

\section{Colaboradores}

E. E. I. Nagahama elaborou o artigo e S. M. Santiago orientou e revisou o artigo final.

\section{Agradecimentos}

Ao Fundo de Apoio ao Ensino, Pesquisa e Extensão da Universidade Estadual de Campinas (FAEPEX/ UNICAMP), pelo apoio financeiro por meio do auxílio linha-pesquisa e auxílio-ponte.
6. Área Técnica da Saúde da Mulher, Secretaria de Políticas de Saúde, Ministério da Saúde. Programa de humanização no pré-natal e nascimento: informações para gestores e técnicos. Brasília: Ministério da Saúde; 2000.

7. Caron OAF. Parturiente e equipe obstétrica: a difícil arte da comunicação [Dissertação de Mestrado]. São Paulo: Universidade de São Paulo; 1998.

8. Murray I, Wilcock A, Kobayashi L. Obstetrical patient satisfaction. J Health Care Mark 1996; 16: 54-7.

9. Kabakian-Khasholian T, Campbell O, Shediac-Rizkallah M, Ghorayeb F. Women's experiences of maternity care: satisfaction or passivity. Soc Sci Med 2000; 51:103-13.

10. Calça AA. O parto humanizado na visão da mulher parturiente [Monografia de Especialização]. Curitiba: Universidade Federal do Paraná; 2001.

11. Gualda DMR, Stefanelli MC. O processo do parto na perspectiva cultural: a experiência de mulheres numa comunidade de baixa renda. In: Merighi MAB, Praça NS, organizadores. Abordagens teórico-metodológicas qualitativas: a vivência da mulher no período reprodutivo. Rio de Janeiro: Editora Guanabara Koogan; 2003. p. 93-105. 
12. Fustinoni SM. As necessidades de cuidado da parturiente: uma perspectiva compreensiva da ação social [Tese de Doutorado]. São Paulo: Universidade de São Paulo; 2000.

13. Alves MTSSB, Silva AAM, organizadores. Avaliação da qualidade de maternidades: assistência à mulher e ao seu recém-nascido no Sistema Único de Saúde. São Luís: Gráfica Universitária da Universidade Federal do Maranhão; 2000.

14. Boaretto MC. Avaliação da política de humanização do parto e nascimento no Município do Rio de Janeiro [Dissertação de Mestrado]. Rio de Janeiro: Escola Nacional de Saúde Pública, Fundação Oswaldo Cruz; 2003.

15. D’Orsi E. Fatores associados à realização de cesáreas e qualidade da atenção ao parto no Município do Rio de Janeiro [Tese de Doutorado]. Rio de Janeiro: Escola Nacional de Saúde Pública, Fundação Oswaldo Cruz; 2003.

16. Dias MAB, Deslandes SF. Expectativas sobre a assistência ao parto de mulheres usuárias de uma maternidade pública do Rio de Janeiro, Brasil: os desafios de uma política pública de humanização da assistência. Cad Saúde Pública 2006; 22: 2647-55.

17. Enkin M, Keirse MJNC, Neilson J, Duley CCLD, Hodnett E, Hofmeyr J. A guide to effective care in pregnancy and childbirth. New York: Oxford University Press; 2005.

18. Tornquist CS. Paradoxos da humanização em uma maternidade no Brasil. Cad Saúde Pública 2003; 19:419-27.

19. McCallum C, Reis AP. Re-significando a dor e superando a solidão: experiências do parto entre adolescentes de classes populares atendidas em uma maternidade pública de Salvador, Bahia, Brasil. Cad Saúde Pública 2006; 22:1483-91.

20. Moraes SDTA. Humanização da assistência materno-neonatal: uma contribuição à sua implantação [Tese de Doutorado]. São Paulo: Universidade de São Paulo; 2005.

21. Cecílio LCO. As necessidades de saúde como conceito estruturante na luta pela integralidade e eqüidade na atenção. In: Pinheiro R, Mattos RA, organizadores. Os sentidos da integralidade na atenção e no cuidado à saúde. Rio de Janeiro: Instituto de Medicina Social, Universidade do Estado do Rio de Janeiro/ABRASCO; 2001. p. 113-26.

22. Rugolo LMSS, Bottino J, Scudeler SRM, Bentlin, MR, Trindade CEP, Perosa GB, et al. Sentimentos e percepções de puérperas com relação à assistência prestada pelo serviço materno-infantil de um hospital universitário. Rev Bras Saúde Matern Infant 2004; 4:423-33.
23. Dias MAB, Domingues RMSM. Desafios na implantação de uma política de humanização da assistência hospitalar ao parto. Ciênc Saúde Coletiva 2005; 10:669-705.

24. Organização Mundial da Saúde. Assistência ao parto normal: um guia prático. Genebra: Organização Mundial da Saúde; 1996.

25. Lima JBMC, Leão MRC. Controle da dor no trabalho de parto e parto. In: Ministério da Saúde, organizador. Anais dos seminários nacionais sobre a assistência obstétrica e neonatal humanizada baseada em evidências científicas. Brasília: Ministério da Saúde; 2005. p. 31-3.

26. Hotimsky SN, Schraiber LB. Humanização no contexto da formação em obstetrícia. Ciênc Saúde Coletiva 2005; 10:639-49.

27. Dias MAB. Humanização da assistência ao parto: conceitos, lógicas e práticas no cotidiano de uma maternidade pública [Tese de Doutorado]. Rio de Janeiro: Instituto Fernandes Figueira, Fundação Oswaldo Cruz; 2006.

28. Carvalho MLM. Participação dos pais no nascimento em maternidade pública: dificuldades institucionais e motivações dos casais. Cad Saúde Pública 2003; 19:389-98.

29. Domingues RMSM. Acompanhantes familiares na assistência ao parto normal: a experiência da Maternidade Leila Diniz [Dissertação de Mestrado]. Rio de Janeiro: Escola Nacional de Saúde Pública, Fundação Oswaldo Cruz; 2002.

30. Brüggemann OM, Parpinelli MA, Osis MJD. Evidências sobre o suporte durante o trabalho de parto/parto: uma revisão da literatura. Cad Saúde Pública 2005; 21:1316-27.

31. Brüggemann OM, Osis MJD, Parpinelli MA. Apoio ao nascimento: percepções de profissionais e acompanhantes escolhidos pela mulher. Rev Saúde Pública 2007; 41:44-52.

32. World Health Organization. Protecting, promoting and supporting breast-feeding. Geneva: World Health Organization; 1989.

33. Corrêa MAP. Relação mãe-bebê no pós-parto: uma contribuição para a Iniciativa Hospital Amigo da Criança [Dissertação de Mestrado]. São Paulo: Instituto de Pesquisa da Secretaria de Estado de Saúde de São Paulo; 2004.

34. Tanaka ACd'A. Maternidade: dilema entre nascimento e morte. São Paulo: Editora Hucitec; 1995.

Recebido em 16/Jul/2007

Versão final reapresentada em 17/Dez/2007

Aprovado em 26/Dez/2007 